\title{
O PNAIC como Política de Formação Continuada no PI: o que revelam os orientadores de estudo acerca das necessidades formativas de professores alfabetizadores
}

\author{
The PNAIC as a Continuing Training Policy in the PI: what the study leaders reveal about the \\ training needs of literacy teachers
}

Le PNAIC comme une Politique de Formation Continue au PI: qui révèlent les conseillers d'étude sur les besoins de formation des professeures d'alphabétisation

Carmen Lúcia de Sousa Lima ${ }^{1}$ Universidade Federal do Piauí

Marcelo Soares Pereira da Silva ${ }^{2}$ Universidade Federal de Uberlândia

Resumo: O artigo discute o Pacto Nacional pela Alfabetização na Idade Certa (PNAIC) como política de formação continuada com ênfase nas necessidades formativas de professores alfabetizadores e objetiva apresentar uma análise da criação e implantação do Programa no Piauí. Para tanto adotamos pesquisa bibliográfica e documental sobre o pacto, e a pesquisa narrativa a partir do memorial de formação das experiências, formação e prática pedagógica dos interlocutores da pesquisa. São analisados e discutidos três aspectos: a contextualização do Pnaic no Brasil e a sua gestão no PI, considerando a formação como um espaço de reflexão docente e os dados de aprovação registrados nos dois anos iniciais do programa.

Palavras-chave: Políticas. Formação Continuada. Necessidades Formativas. Professores Alfabetizadores.

Abstract: The article discusses the National Pact for Literacy in the Right Age (PNAIC) as a policy of continuous training with emphasis on the training needs of literacy teachers and aims to present a brief analysis of the creation and implementation of the Program in the Piauí. In order to do so, we adopted bibliographic and documentary research on the pact, and the narrative research based on the formation of the experiences, training and pedagogical practice of the research interlocutors. Three aspects are analyzed and discussed: the contextualization of Pnaic in Brazil and its management in the PI, considering training as a space for teacher reflection and the approval data recorded in the first two years of program.

Keywords: Policies. Continuing Education. Formative Needs. Teachers Literacy.

Résumé : L'article traite du Pacto Nacional pela Alfabetização na Idade Certa (PNAIC) comme une politique de formation continue, en se concentrant sur les besoins de formations des professeurs d'alphabétisation et et vise à présenter une brève analyse de la création et de la mise en œuvre du Programme au Piauí. À cette fin, nous avons adopté des études bibliographiques et documentaires sur le pacte, ainsi que de l'étude narrative à partir du

\footnotetext{
${ }^{1}$ Mestre em Educação. Professora da Universidade Federal do Piaú́ (UFPI).E-mail: carmenlima5@yahoo.com.br

2 Doutor em Educação. Professor Associado da Universidade Federal de Uberlândia (UFU). E-mail: marcelospsilva@hotmail.com
} 
mémorial de formation des expériences, de la formation et de la pratique pédagogique des interlocuteurs d'étude. Trois aspects sont analysés et discutés: la contextualisation de PNAIC au Brésil et sa gestion au Piaú, considérant la formation comme un espace de réflexion pour les professeurs et les données d'approbation enregistrées au cours des deux premières années du programme.

Clés-mots : Politique. La Formation Continue. Les Besoins de Formation. Les Professeures d'alphabétisation.

\section{Introdução}

A formação do professor alfabetizador ocupa um espaço de destaque nas discussões sobre a educação de qualidade (BRITO (2006; 2007), BRITO e MELO (2016), GARCÍA (2008), KRAMER, 2010), dentre outros, considerando que a alfabetização é a base do processo de escolarização bem sucedida, devendo ser pautada nos conhecimentos teórico-metodológicos da educação e da alfabetização.

Tal formação justifica-se em razão das diversas demandas da prática, considerando que a alfabetização tem se constituído em um problema social de difícil solução, sendo alvo de diversos estudos, portanto, um tema atual dado aos altos índices de analfabetismo apresentados nas pesquisas sobre a temática (KRAMER, 2010).

No Brasil, a alfabetização de crianças tem se constituído em um dos principais desafios das políticas educacionais. Esse desafio é evidenciado nos resultados de avaliações em larga escala, como na Prova Brasil e na política censitária. A análise da trajetória da educação brasileira revela uma dura realidade que nos coloca diante de um quadro educacional trágico, no que diz respeito à aquisição da leitura e da escrita, visto que muitas crianças e adolescentes concluem o processo de escolarização sem estarem plenamente alfabetizadas, resultando em repetência escolar e, consequentemente, no déficit de aprendizagem em relação à série cursada, conforme atestam os dados a seguir: Quase 60\% dos alunos brasileiros apresentavam baixa proficiência em leitura (Pisa, 2009); Língua Portuguesa: $5^{\circ}$ ano = 4,7 (Prova Brasil, 2011); A taxa de analfabetismo era de $3,9 \%$, entre pessoas com 10 a 14 anos de idade, e de $9,6 \%$, entre pessoas com 15 anos ou mais (IBGE, 2011); Prova ABC 2011 (Avaliação Brasileira do Final do Ciclo de Alfabetização) - mais de 40\% não tinha a capacidade de leitura esperada para a etapa. 
Os dados apontam para uma problemática que levanta a seguinte questão: até que ponto o poder público está cumprindo com o seu compromisso de garantir a aprendizagem da leitura e da escrita? Uma série de justificativas baseadas em "teorias do déficit" supunha que a aprendizagem dependeria de pré-requisitos (cognitivos, psicológicos, perceptivo-motores, linguísticos...), assim como a pobreza, os problemas afetivos e familiares e na falta de interesse da família pela vida escolar dos filhos, e, que as crianças que fracassavam o faziam por não dispor dessas habilidades prévias.

Com efeito, os dados obtidos em avaliações censitárias e de larga escala que apontam os rendimentos dos alunos das escolas brasileiras servem de orientação para a formulação e implantação das políticas educacionais. Dentre tais avaliações destacam-se duas sobre a aquisição da língua oral e escrita de crianças e jovens realizada pelo Sistema Nacional de Estudos e Pesquisas Educacionais e desenvolvidas pelo INEP - Instituto Nacional de Estudos e Pesquisas Educacionais Anísio Teixeira: o SAEB - Sistema de Avaliação da Educação Básica e a Provinha Brasil (PIRES; SCHNECKENBERG, 2015).

O estudo parte da seguinte problemática: quais as necessidades formativas de professores alfabetizadores que participaram do Pacto Nacional pela Alfabetização na Idade Certa no PI e como as ações formativas dessa política têm contribuído para o redirecionamento das práticas dos alfabetizadores, bem como com a melhoria dos indicadores de aprovação? Assim, o presente estudo objetiva apresentar uma breve análise da criação e implementação do Programa no estado, refletindo acerca das necessidades formativas de professores alfabetizadores que participaram do Pacto e como as ações formativas do programa têm contribuído para o redirecionamento das suas práticas levando em conta o aumento dos indicadores de aprovação.

Para a realização do estudo adotamos como metodologia a pesquisa narrativa e a pesquisa bibliográfica e documental. A pesquisa narrativa consiste em dar voz aos interlocutores valorizando suas experiências de vida, formação e prática pedagógica. Conforme Souza (2006), as narrativas oportunizam aos interlocutores narrar acontecimentos relacionados à vida, a formação e a prática profissional. A pesquisa narrativa, no contexto da formação de professores, possibilita compreender como esses profissionais dão sentido ao seu trabalho e conhecer suas necessidades formativas, nesse caso dos professores alfabetizadores cursistas do PNAIC no PI. Para tanto, envolvemos no estudo 22 orientadores de estudo, utilizamos como instrumento de coleta de dados: o memorial de formação, logo após a sua 
escrita procedemos com a leitura e análise interpretativa das narrativas de formação dos professores orientadores.

A metodologia do trabalho contempla, ainda, a pesquisa bibliográfica que, segundo Gil (2008), é desenvolvida com base em material já elaborado, constituído principalmente de livros, textos e artigos científicos. O estudo contou, também, com a pesquisa documental que, segundo Gil (2002), se assemelha à pesquisa bibliográfica, a diferença essencial entre as duas está na natureza das fontes. Esta pesquisa documental objetivou o estudo dos documentos e marcos regulatórios referentes ao PNAIC, como: Portaria $n^{\circ} 867$ de 4 de julho de 2012, que institui o Pacto; A Medida Provisória n 586 de 8 de novembro de 2012 que dispõe sobre o apoio técnico e financeiro da União aos entes federados; Formação de Professores no Pacto pela Alfabetizaçãona Idade Certa 2012; Documento Orientador das Ações de Formação em 2014,entre outros.

\section{Contextualizando o PNAIC no Brasil}

O desenho da política educacional no Brasil está pautado em um conjunto de mudanças na estrutura social, econômica e política e evidenciam necessidades que objetivam uma articulação entre a realidade do trabalho e a qualidade da educação no sentido de alcançar metas traduzidas em resultados. Essa articulação se dá no contexto de consolidação das reformas efetivadas no Brasil a partir da década de 1990, com a implementação de uma política educacional mais abrangente do que a legislação proposta para organizar a área. Assim, para o desenvolvimento dessas políticas fez-se necessário o planejamento educacional e o financiamento de programas governamentais nas três esferas (Federal, Estadual e Municipal), a partir dos seguintes eixos: gestão, currículo e avaliação.

É, portanto, nesse contexto de reformas que as políticas de formação continuada se inserem e são referendadas na LDB 9394/96 (Brasil, 2006), no Título VI dessa Lei, que trata sobre os profissionais da educação, estabelecendo que os sistemas de ensino deverão promover a valorização dos profissionais da educação, assegurando-lhes o aperfeiçoamento profissional continuado, com um período reservado a estudos, planejamento e avaliação, incluído na carga de trabalho, ao tempo em que reconhece a necessidade de uma política de formação continuada através da articulação dos entes federados.

A implementação das diversas políticas de formação não se dá de forma descontextualizada. Tem base histórica em condições emergentes na sociedade 
contemporânea, nos desafios colocados aos currículos e ao ensino, nos desafios postos aos sistemas pelo acolhimento cada vez maior de crianças e jovens, nas dificuldades do dia-a-dia nos sistemas de ensino, anunciadas e enfrentadas por gestores e professores e constatadas e analisadas por pesquisas (GATTI, 2008).

Nesse âmbito, elaborou-se um conjunto de propostas oficiais traduzidas em ações de formação continuada de professores em serviço que visavam, além da aquisição de novos conhecimentos, a melhoria da prática com o desenvolvimento de novas estratégias pedagógicas. Destarte, grande esforço governamental tem sido feito no sentido de elevar o nível da formação docente, para isso várias ações foram implementadas na última década no sentido de viabilizar a formação em serviço daqueles que atuam no magistério da Educação Básica nas Redes Públicas de ensino, dentre outras iniciativas globais como: Declaração de Dakar - Educação Para Todos (2000); Objetivos de Desenvolvimento do Milênio (ODM) (2010); Alfabetização para o Empoderamento (Life) (2011) e a Década das Nações Unidas para a Alfabetização (2003-2012). O Monitoramento da Década de Alfabetização no Brasil se deu através de Sistemas de avaliação padronizada, elaborados e implementados tanto por organizações e programas internacionais, quanto por órgãos governamentais e por organizações não-governamentais brasileiras.

As políticas educacionais traçadas pelo Governo Federal, bem como pelos governos estaduais e municipais, têm priorizado o problema do fracasso dos alunos nos primeiros anos do Ensino Fundamental. Nesse sentido, diversos projetos vêm sendo implementados nas redes de ensino de todo o país. Alguns desses projetos têm trazido impactos diretos para as práticas de alfabetização e para as propostas de formação continuada de professores.

Nesse contexto, se situa o Pacto Nacional Pela Alfabetização na Idade Certa - PNAIC, compromisso do Plano de Desenvolvimento da Educação - PDE de 2007 e meta do novo Plano Nacional de Educação - PNE (Brasil, 2014), cujo objetivo se constituiu em alfabetizar as crianças até, no máximo, os oito anos de idade, ou seja, ao final do $3^{\circ}$ ano do ensino fundamental. Nesse sentido, o Ministério da Educação-MEC, no seu papel de indutor de políticas educacionais propôs, no ano de 2012, o PNAIC nas áreas de Linguagem e Matemática, oferecendo suporte técnico e financeiro. A gestão do Pacto é de competência do Ministério da Educação - MEC em parceria com universidades que integram a Rede Nacional de Formação Continuada com adesão dos Estados, Municípios e Distrito Federal, podendo participar todos os professores em efetivo exercício nos três primeiros anos iniciais do ensino fundamental da 
rede pública de ensino. As ações do PNAIC apoiam-se em quatro eixos: Formação continuada; Gestão, controle social e mobilização; Avaliação Sistemática e materiais didáticos.

A formação continuada dos professores alfabetizadores do pacto ocorre por meio de curso presencial, com duração de dois anos com carga horária anual de 120 horas, ministrado por profissionais oriundos das universidades públicas e das redes de ensino. A formação de professores alfabetizadores é realizada pelos orientadores de estudo (professores das redes) que participaram de um curso específico com carga horária de 200 horas anuais, tendo como referência, conhecimentos relacionados a alfabetização e letramento em língua portuguesa, matemática, ciência e artes.

Conforme consta no Documento Orientador das Ações de Formação de 2014 do PNAIC, o primeiro eixo da formação continuada de professores conta com conteúdos que auxiliam o debate frente aos direitos de aprendizagem dos alunos do ciclo de alfabetização; processos de avaliação e acompanhamento da aprendizagem das crianças; planejamento e avaliação das situações didáticas e o conhecimento e uso de materiais disponibilizados pelo MEC, voltados para a melhoria da qualidade do ensino no ciclo de alfabetização.

No ano de 2013, de implementação do PNAIC, os conteúdos da formação continuada/PNAIC tiveram como eixo a Língua Portuguesa com ênfase em conhecimentos relacionados a aprendizagem do Sistema de Escrita Alfabética, as contribuições da teoria da psicogênese da escrita para compreensão do processo de apropriação do Sistema de Escrita Alfabética, alfabetização e letramento. Além disso, outros conhecimentos foram contemplados na formação e envolveram: o currículo nos anos iniciais do ensino fundamental na perspectiva da educação inclusiva, a valorização das diversidades, a avaliação no ciclo de alfabetização, analisando e construindo instrumentos de avaliação e registro de aprendizagem, a educação do campo e alfabetização em classes multisseriadas, entre outros (BRASIL, 2012).

Em 2014, o foco da formação foi Alfabetização Matemática na perspectiva do letramento, trabalhado em consonância com o material de formação em linguagem (Língua Portuguesa). A abordagem partiu do princípio de que conceitos e habilidades matemáticas são necessários para que a criança possa ser considerada alfabetizada. Além do letramento matemático, a formação objetivou ampliar as discussões sobre a alfabetização, na perspectiva do letramento, tanto em relação à Língua Portuguesa, quanto no que tange à Matemática. Os conteúdos na área do letramento matemático contemplaram: organização do trabalho pedagógico, quantificação, registros e agrupamentos, construção do sistema de numeração decimal, operações e resolução de problemas, grandezas e medidas, educação estatística e 
saberes da matemática, entre outros campos do saber (BRASIL, 2014).

Já em 2015, a formação continuada de alfabetizadores ampliou as discussões sobre a alfabetização e o letramento, numa perspectiva interdisciplinar, no que tange a questões teóricas e metodológicas. A formação focalizou, também, os princípios de gestão e da organização do ciclo de alfabetização. Entre os temas que foram trabalhados destacam-se o currículo na perspectiva da educação inclusiva, da valorização da diversidade, a criança no ciclo da alfabetização, a interdisciplinaridade e o papel da gestão nos processos de alfabetização das crianças (BRITO e MELO, 2016).

\section{A gestão do PNAIC NO Piauí: atuação docente reflexiva}

No que tange a formação continuada de professores em serviço, esta constitui-se em um espaço permanente de formação reflexiva do professor perante as múltiplas exigências educacionais, cujas necessidades formativas requerem mudanças significativas na prática pedagógica dos professores, já que têm a oportunidade de discutir não somente os problemas relacionados à sala de aula, mas também a ressignificação de suas concepções acerca da educação como um todo, em especial das suas práticas.

Nesse sentido, Brito e Melo (2016) afiançam que, em face do reconhecimento do papel do professor nos processos de ensinar/aprender, como um dos principais agentes capazes de materializar as ações que se destinam a garantir a alfabetização na idade certa, sua formação passou a ser considerada uma ação necessária e estratégica. Essa compreensão fundamenta-se na ideia de que a formação de professores pode provocar transformações nas orientações dos sistemas educativos, na cultura escolar, nos métodos de ensino e, consequentemente, no desenvolvimento profissional dos professores.

Pires e Schneckenberg (2015), ao sustentarem uma concepção de formação continuada crítica-reflexiva, confirmam que a busca ao progresso profissional do docente traz em seu âmago uma rede de relações, o trabalho conjunto da escola, alunos, professores com seus pares e sociedade, para além do trabalho pedagógico. Contudo, as autoras supracitadas, evidenciam a importância de uma formação que ofereça meios para que o docente compreenda que a solução dos problemas e dificuldades encontradas no cotidiano está além de uma atualização teórica e didática, pois demanda a criação de espaços propulsores de mudanças, fortalecendo assim, o conceito de formação continuada. 
Brito e Melo (2016), asseveram que embora a LDB/96 destaque a preocupação com a formação de profissional docente, ainda assim, os investimentos na formação continuada carecem de ampliação, da definição de políticas públicas, cujas metas preocupem-se com o aprendizado docente ao longo da carreira e de uma sintonia com as práticas docentes e com as necessidades formativas dos professores.

Assim, com o propósito de analisar as necessidades formativas de professores alfabetizadores, bem como as contribuições da formação continuada de alfabetizadores, notadamente no âmbito do Pacto Nacional pela Alfabetização na Idade Certa no Piauí, para o redimensionamento das práticas alfabetizadoras, lançamos mão do memorial de formação.

Para a escrita do memorial de formação, algumas questões foram elencadas: qual a sua concepção de formação continuada? Que dificuldades os professores alfabetizadores apresentam para ensinar a linguagem em sala de aula? Que necessidades os professores apresentam em sua prática alfabetizadora? De que forma o PNAIC tem contribuído com o redimensionamento da prática pedagógica do professor alfabetizador? Que ações vêm sendo desenvolvidas no âmbito da gestão municipal, para que a formação continuada do PNAIC seja efetivada? As respostas a essas questões nortearam as nossas análises e reflexões acerca das necessidades formativas dos professores orientadores e da importância da formação continuada.

Os orientadores de estudo compreendem a formação continuada como um espaço de formação em serviço, oportunizando aos docentes refletirem sobre a prática pedagógica e a troca de experiências, o que contribui para o redirecionamento da prática. A esse respeito García (2008), pontua que a formação em serviço deve possibilitar aos professores à reflexão sobre a prática, no sentido de transformá-la. Os relatos dos interlocutores denotam que os professores alfabetizadores tinham dificuldades em trabalhar a alfabetização e o letramento, pois não dominavam os conhecimentos teórico-metodológicos relativos à alfabetização e o letramento.

Nas narrativas os interlocutores são unânimes em destacar que o PNAIC, tem contribuído para a melhoria do ensino na alfabetização, oportunizando os alfabetizadores, a partir da formação, redirecionar as práticas pedagógicas, enfatizam que o PNAIC é um programa completo, pois oferece a formação, o monitoramento e os materiais necessários ao trabalho na alfabetização. Os interlocutores pontuam que os gestores municipais, na sua maioria tem dado as condições para que o pacto aconteça, porém nos municípios que o gestor não tem dado apoio, a formação tem acontecido também com qualidade. $\mathrm{O}$ aspecto presente 
nas narrativas é a ênfase dada à formação de matemática, como sendo indispensável ao letramento dos alunos.

\subsection{O que revelam os dados do PNAIC no Piauí}

O desenho da proposta de formação do PNAIC no Piauí contemplou um número significativo de professores que através do delineamento de ações formativas nessa ordem: (formador que forma o orientador de estudo, que forma professor alfabetizador), surgiram uma série de dificuldades para a garantia da qualidade dos processos formativos, dificuldades essas relatadas nas narrativas de alguns dos orientadores de estudos. Nesse sentido, se faz urgente a necessidade de ampliar o compromisso dos gestores públicos e com isso assegurar condições de trabalho que viabilizem o desenvolvimento das ações do Pacto, sobretudo, a realização da formação continuada de professores no âmbito dos municípios.

Entretanto, Melo e Brito (2016) consideram que apesar das dificuldades encontradas, os resultados são visíveis e crescentes, ao tempo em que destacam o impacto das ações do PNAIC para a melhoria dos dados de rendimento escolar no Estado do Piauí tendo como referência o ano anterior à implantação do Programa (ano de 2012) e anos posteriores (2013 e 2014) a implementação de suas ações, conforme dados de aprovação registrados na Tabela 01:

Tabela 01 - Dados de aprovação escolar.

\begin{tabular}{|l|l|l|l|}
\hline ANO & $\mathbf{1}^{\mathbf{o}}$ ANO & $\mathbf{2}^{\mathbf{o}}$ ANO & $\mathbf{3}^{\mathbf{o}}$ ANO \\
\hline $\mathbf{2 0 1 2}$ & $90,8 \%$ & $85,9 \%$ & $79,4 \%$ \\
\hline $\mathbf{2 0 1 3}$ & $96,1 \%$ & $94,1 \%$ & $81,3 \%$ \\
\hline $\mathbf{2 0 1 4}$ & $96,1 \%$ & $93,9 \%$ & $78,4 \%$ \\
\hline
\end{tabular}

Fonte: Brito e Melo, 2016

A análise da Tabela 01 apresenta crescimento significativo nas taxas de aprovação escolar, principalmente nos dois primeiros anos no ciclo da alfabetização (2013 e 2014). No $1^{\circ}$ ano a aprovação subiu de 90,8\% em 2012 para 96,1\% em 2014. No $2^{\circ}$ ano também houve crescimento de 85,9\% em 2012 para 93,9\% em 2014. No $3^{\circ}$ ano houve um avanço de $2 \%$ em 2013, em relação a 2012, ano anterior à implantação do Pacto no Estado. 


\section{Considerações finais}

A formação do professor alfabetizador demanda conhecer as teorias da educação e da pedagogia da alfabetização, compreendendo que o objetivo da alfabetização é dotar os alunos da capacidade de interagir em situações sociais de leitura e escrita, de modo que estes desenvolvam habilidades e competências que contribuem com o desenvolvimento da aprendizagem dos alunos do $1^{\circ}$ Ciclo da Alfabetização e a melhoria da qualidade na educação.

Assim, é que se faz necessário, a implantação de políticas de formação continuada diversificadas que envolvam igualmente uma diversidade de profissionais da educação com diferentes tipos de ações. Comporta realçar que para que as ações sejam eficazes é necessário que as políticas de formação sejam pautadas tomando como base os resultados das avaliações, garantido também, que a prática docente seja considerada um eixo central na definição e redefinição das políticas de formação.

Tendo em vista que a alfabetização vem se destacando nos espaços de discussões sobre políticas públicas de educação é premente uma maior participação dos gestores em todas as esferas na viabilização e implementação das ações do Pacto, perspectivando avançar na construção de uma proposta que contemple a alfabetização como um direito social por meio do qual é possível garantir outros direitos.

É pertinente destacar, ainda, que a concretização das ações indicadas no conjunto de metas do PNAIC coloca o docente como protagonista do processo de formação e como condicionante, o comprometimento e a atuação dos professores sem, contudo, evidenciar que para o desenvolvimento de uma política de formação que contribua tanto com a melhoria da qualidade da educação, quanto com a valorização dos professores, deve ser acompanhada de maiores investimentos na área, pois quanto maior o volume de investimentos na formação, maiores serão as perspectivas de avanços na educação.

\section{Referências}

BRASIL. Lei de Diretrizes e Bases da Educação Nacional - Lei n. 9.394 de 20 de dezembro de 1996. Disponível em: <HTTP://www.presidencia.gov./o3/Leis/L9394.htm>. Acesso em: 15 jun. 2013.

BRASIL. Secretaria de Educação Básica. Diretoria de Apoio à Gestão Educacional. Pacto Nacional pela alfabetização na idade certa: formação do professor alfabetizador: caderno de apresentação / Ministério da Educação, Secretaria de Educação Básica, Diretoria de Apoio à Gestão Educacional. - Brasília: MEC, SEB, 2012 a. 
BRASIL. MINISTÉRIO DA EDUCAÇÃO (MEC). Portaria nº 867, de 4 de julho de 2012. Institui o Pacto Nacional pela Alfabetização na Idade Certa e as ações do Pacto e define suas diretrizes gerais. Diário Oficial da União, 2012b.

BRASIL. Lei no 13.005. de 25 de junho de 2014. Aprova o Plano Nacional de Educação (PNE) e dá outras providências. Brasília: Diário Oficial [da] República Federativa do Brasil, Brasília, 26 de jun. 2014b. Seção 1, p.1, Ed. Extra.

BRASIL. O Plano de Desenvolvimento da Educação: razões, princípios e programas. Brasília: MEC, 2007.

BRITO, A. E. Formação do docente alfabetizador: revelando as exigências e os desafios. In: $I V$ Encontro de Pesquisa em Educação da UFPI, 2006, Teresina/PI. Livro de resumo. Teresina: Ed. UFPI, 2006. p. 1-10. v. 1.

BRITO, A. E. Prática pedagógica alfabetizadora: a aquisição da língua escrita como processo sociocultural. In: Revista Iberoamericana de Educación. Organización de Estados Iberoamericanos para laEducación, laCiencia y la Cultura (OEI). n. 44/4 - 10 de noviembre de 2007. Disponível em: <http://www.rieoei.org/deloslectores/1877Brito.pdf>. Acesso em: 08 abr. 2013.

BRITO, A. E.; MELO R. A. de. Formação continuada de professores e o delineamento das políticas de alfabetização. In: Formação continuada de professores: desafios da alfabetização na idade certa. Antonia Edna Brito e Raimunda Alves Melo (Orgs.). Teresina: EDUFPI, 2016. P. 22- 46.

CHU, S. K.; BAJRACHARYA, R. Regional Mid-Term Evaluation of Literacy Initiative for Empowerment (LIFE). Bangkok: UNESCO Asia-Pacific Regional Bureau for Education, 2011. Disponível em: http://uil.unesco.org/fileadmin/keydocuments/Literacy/LIFE/MidtermPackage/3_asia_regional_and_country_reports/3a_\%20Regional_\%20report_Asia/LI FE_Midterm_Evaluation_\%20Report_Asia_Pacific.pdf. Acesso em: 09 set. 2018

DECLARAÇÃO, DE DAKAR. Educação para todos-2000. Educação, 2012. Disponível Em: http://unesdoc.unesco.org/images/0012/001275/127509porb.pdf Acessada em 29/04/2015Acesso em: 09 set. 2018.

DECLARAÇÃODO MILÊNIO, Objetivos de Desenvolvimento. Relatório nacional de acompanhamento. Brasília: Ipea, 2010. Disponível em: http://ba.one.un.org/content/dam/undp/library/MDG/english/MDG\%20Country\%20Re ports/Brazil/brazilinformenacionalodm2005.pdfAcesso em:09 set. 2018.

GARCIA, R. L.A formação da professora alfabetizadora: reflexões sobre a prática. São Paulo: Cortez, 2008.

GATTI, B. A. Análise das políticas públicas para formação continuada no Brasil, na última década. Fundação Carlos Chagas. In: Revista Brasileira de Educação v. 13 n. 37 jan./abr. 2008.

GIL, A. C. Como elaborar projetos de pesquisa. 4. ed. São Paulo: Atlas, 2002. 
GIL, A. C. Métodos e técnicas de pesquisa social. 6. ed. São Paulo: Atlas, 2008.

Instituto Brasileiro de Geografia e Estatística (IBGE). Sinopse do Censo Demográfico, 2011 Disponível em https://ww2.ibge.gov.br/home/estatistica/populacao/censo2010/default.shtm. Acesso em:09 set. 2018.

Instituto Nacional de Estudos e Pesquisas Educacionais Anísio Teixeira (INEP). Programa Internacional de Avaliação de Alunos (Pisa): resultados nacionais - Pisa 2009 / Instituto Nacional de Estudos e Pesquisas Educacionais. - Brasília: O Instituto, 2012. 126 p.: il.

Instituto Nacional de Estudos e Pesquisas Educacionais Anísio Teixeira (INEP). Prova Brasil 2011. Disponível em: http://portal.inep.gov.br/artigo//asset_publisher/B4AQV9zFY7Bv/content/inep-divulga-resultados-preliminares-daprova-brasil-2011/21206 acesso em:09 set. 2018.

KRAMMER, S. Alfabetização, leitura e escrita formação de professores em curso. São Paulo: Ática, 2010.

PIRES, A. de P.; SCHNECKENBERG, M. Política de formação continuada de professores: o Pnaic e o desafio da alfabetização a idade certa. In: CAMINE: Cam. Educ. = CAMINE: Ways Educ., Franca, SP, Brasil - e ISSN 2175-4217.

SOUZA, E. C. de. O conhecimento de si: estágio e narrativas de formação de professores. Rio de Janeiro: DP\&A: Salvador (BA); UNEB, 2006. 